Revista de Derecho de la Pontificia Universidad Católica de Valparaíso

52 (primer semestre de 2019)

[pp. 35 - 56]

\title{
DereCHO, ECONOMÍA Y ÉTICA DE LOS NEGOCIOS. UNA RELACIÓN NECESARIA PARA EL MERCADO DE VALORES
}

[Law, economy, and business ethics. A necessary relationship for the stock market]

\author{
Adolfo Silva Walbaum* \\ Pontificia Universidad Católica de Valparaíso \\ Juan Pablo Faúndez Allier** \\ Pontificia Universidad Católica de Valparaíso
}

\begin{abstract}
RESUMEN
Este trabajo busca precisar qué debe entenderse bajo el concepto de normas éticas comerciales, tanto de manera general para efectos jurídicos, como en particular, para la legislación del mercado de valores. Para ello, se aborda la relación existente entre derecho y economía en tanto ciencias sociales insertas dentro del modelo económico capitalista y, desde ahí, se busca precisar el contenido y extensión del efecto jurídico de las normas éticas en el ámbito del tráfico mercantil. Conjuntamente, se efectúa una referencia a la autorregulación, para así precisar cuáles serían los ámbitos concretos bajo los cuales el derecho encuentra respuesta precisa a la necesaria relación existente entre ciencia jurídica, ciencia económica y ética de los negocios.
\end{abstract}

\begin{abstract}
This work looks to precisely define what should be understood under the concept of norms in business ethics, both for general legal effects and for particular stock market legislation. To do so, the authors look at the existing relationship between law and economy as social sciences inserted within the context of the capitalist economic model and, from this base, to specify the content and extent of the legal effects of ethic norms in the context of market law. Simultaneously, the paper makes use of a double reference to self-regulation, in order to indicate for which specific contexts law would have the precise response to the necessary existing relationship among legal science, economic science, and business ethics.
\end{abstract}

RECiBido el 28 de abril de 2017 y aceptado el 7 de enero de 2019

* Doctor en Derecho por la Universidad de Granada (España). Magíster en Derecho por la Pontificia Universidad Católica de Chile. Abogado por la Pontificia Universidad Católica de Valparaíso (Chile). Profesor de Derecho Comercial y Económico de la Facultad de Derecho de la Pontificia Universidad Católica de Valparaíso (Chile). Dirección postal: Avenida Brasil 2950, Valparaíso, Chile. Correo electrónico: adolfo.silva@pucv.cl. 
Palabras Clave

Derecho Económico - derecho economía - ética de los negocios - mercado - valor.
KEYWORDS

Economic Law - law - economy business ethics - market - value.

\section{INTRODUCCIÓN}

En tiempos de crisis ${ }^{1}$, la búsqueda de respuestas concretas frente a comportamientos que a priori resultan disruptivos, se torna más urgente. A diario recibimos noticias en las que se pone de manifiesto la falta de

** Doctor en Filosofía por la Universidad de Salamanca (España) Máster en Derecho Canónico por la Universidad Pontificia de Salamanca (España). Abogado y Licenciado en Filosofía por la Pontificia Universidad Católica de Chile. Profesor de Ética, Bioética y Derecho Canónico de la Facultad Eclesiástica de Teología de la Pontificia Universidad Católica de Valparaíso. Dirección postal: Avenida Brasil 2950, Valparaíso, Chile. Correo electrónico: juan.faundez@pucv.cl.

Los autores agradecen especialmente a los alumnos de la Escuela de Derecho de la Pontificia Universidad Católica de Valparaíso, doña Camila Quijano, don Pablo Hernández y don José Luis Caamaño, por su valioso aporte en la realización de esta investigación.

${ }^{1}$ Es precisamente en tiempos de crisis cuando se revaloriza el concepto y preocupación por lo ético. Por la misma razón no es de extrañar que desde que estallara la quiebra de Lehman Brothers -en septiembre del año 2008- desde diversos sectores de la economía norteamericana, primero, y de la internacional, después, se ha ido acentuado la preocupación por lo ético, aun cuando su origen sea de antigua data. En efecto, ya con los fraudes de las empresas Enron y Worldcom en 2001, y antes de aquello, desde la década de los setenta y noventa del siglo XX, ya se venía planteando esta preocupación por la existencia de un comportamiento correcto por parte de los agentes del mercado. Como nos recuerda González, María, Ética de la economía, sujeto y derechos humanos, en Revista de la Universidad Bolivariana 11 (2012), 33, p. 243: "Desde los noventa se vienen planteando con mayor fuerza por parte de grupos académicos y de amplios sectores de la sociedad civil organizada los grandes dilemas éticos de nuestro tiempo". En el mismo sentido, pero más enfocado a la función del Derecho en este tipo de situaciones, Fernández, Luis, Derecho, ética y negocios (Discurso de apertura del año académico 1993-1994). Disponible [en línea]: http:// www.cervantesvirtual.com/obra-visor/derecho-etica-y-negocios--0/html/ff26d28882b1-11df-acc7-002185ce6064_1.html; y entiende que: "Sea cual fuere la decisión que se adopte, asistimos desde hace años a un proceso de convergencia entre las normas éticas y las normas jurídicas como instrumentos de ordenación y gobierno del mundo de los negocios. Ello suscita en el ámbito de la sociología jurídica importantes cuestiones teóricas, que se anudan básicamente a la exigencia o no de una mayor juridificación de la vida social y económica de nuestros días y, en particular, a la necesidad o conveniencia de establecer nuevos instrumentos de control sobre el funcionamiento del mercado". 
confianza, o la existencia de alguna deslealtad o mala fe. Por tal motivo, no resulta extraño que, cada vez con más fuerza, se espere una solución concreta por parte del derecho que efectivamente permita responder a todas aquellas conductas que puedan ser consideradas como faltas de ética ${ }^{2}$.

Lo señalado resulta mucho más complejo y de imprescindible necesidad de resolución, desde que esta serie de acciones inadecuadas se circunscriben a un ámbito marcado por el desarrollo de actividades de carácter lucrativo, tal como es el caso del derecho del mercado en general y, particularmente, del denominado derecho del mercado de valores ${ }^{3}$. Desde ahí surge la imperiosa necesidad por tratar de comprender qué debe entenderse por principios de ética comercial, establecidos en los artículos 43 y 44 de la Ley de mercado de valores ${ }^{4}$ de Chile -en adelante LMV $^{5}$ - y que son jus-

${ }^{2}$ En la misma línea, hoy somos testigos de una especie de desconfianza generalizada que se ha instalado hacia los empresarios, la que se sustenta en la idea de que muchos de ellos estarían dispuestos a efectuar cuestionables comportamientos con tal de conseguir el éxito económico y, por sobre todo, alcanzar la máxima rentabilidad en sus negocios independientemente de los medios con que ello se obtenga. Lo anterior ha venido a conformar una situación distinta para los agentes del mercado, de la cual el derecho también debe hacerse cargo.

${ }^{3}$ Según Cachón, José, Derecho del mercado de valores (Madrid, Dykinson, 1992), I, p. 26, el derecho del mercado de valores es: "el conjunto de normas que regulan las instituciones intervinientes en este mercado, los activos propios del mismo, y las operaciones que se desarrollan en él". Acerca de la noción de valor y título valor, recomendamos al lector ver: GUZMÁn, Alejandro - GUERRERO, José Luis, La sustitución de la noción de "título-valor" por "valores negociables" en la ley de mercado de valores de España, como base para la delimitación de un derecho del mercado de valores, en RDUCN. 24 (2017), pp. 211-237, y, GuZMÁN, Alejandro - Guerrero, José Luis, La noción de "valor" como objeto de transacción en el mercado de valores según el derecho chileno, en RDPUCV. 47 (2016), pp. 37-55.

${ }^{4}$ Según Lidón, Jesús, Conceptos básicos de Economía (Valencia, Universidad Politécnica de Valencia, 1998), p. 55, entiende por mercado de valores: "El conjunto ideal de actos de compra y venta de unos bienes económicos concretos, en tiempo y espacio determinados".

${ }^{5}$ Ley N 18.045 (LMV) del 22 de octubre de 1981. 
tamente a los cuales tanto la bolsa de valores ${ }^{6}$ como sus miembros, agentes o intermediarios deben someter su actuar ${ }^{7}$.

La respuesta a esta pregunta nos ayudará a comprender una inquietud que no solamente sirva de guía al derecho comercial o al derecho económico -en tanto ramas y asignaturas del derecho ${ }^{8}$ - sino que también contribuya a esclarecer cómo debe entenderse una necesaria vinculación entre el derecho y la ética de los negocios?

${ }^{6}$ Efectivamente, de conformidad al artículo 43 de la LMV: "Para desarrollar su objeto, las bolsas de valores, a lo menos, deberán: c) Velar por el estricto cumplimiento por parte de sus miembros de los más elevados principios de ética comercial y de todas las disposiciones legales y reglamentarias que les sean aplicables". Por su parte, el artículo 44 de la LMV agrega que: "En la reglamentación de sus propias actividades y las de sus miembros, las bolsas de valores deberán contemplar normas, sobre las materias que a continuación se indican: $b$ ) Normas tendientes a promover principios justos y equitativos en las transacciones de bolsa, y a proteger a los inversionistas de fraudes y otras prácticas ilegitimas. c) Normas y procedimientos justos y uniformes por los cuales los miembros de una bolsa de valores y los socios y empleados de éstos, puedan ser sancionados, suspendidos o expulsados de ella en caso que hayan incurrido en infracción a la presente ley y sus normas complementarias o de los estatutos o normas internas de la misma".

${ }^{7}$ Como recuerda García, María Nieves, Ética, equidad y normas de conducta en los mercados de valores: la regulación del abuso del mercado, en Revista Ética y Economía 823 (2005), p. 167: "Desde el inicio de la actividad de las bolsas, los agentes de mercado efectuaron prácticas dudosas, como actuaciones concertadas o difusión de rumores falsos. Aunque en algunos países la manipulación era ilegal, muchas fortunas hechas en los siglos XVIII y XIX deben el éxito a su práctica. El crac bursátil de 1929 llevó a plantear la cuestión de la manipulación, ya que muchos pensaron que los rumores y ventas concertadas que tuvieron lugar entonces contribuyeron a aumentar su magnitud. En la investigación realizada por el comité del Senado en banca y moneda de Estados Unidos se puso de manifiesto que era común la práctica de comprar un valor, difundir un rumor y luego venderlo con beneficio. El resultado fue la prohibición de esta práctica en la Securities Exchange Act de 1934. Esta ley divide la manipulación en dos categorías. La primera es la manipulación basada en actuaciones que modifican el valor actual o percibido de los valores. El segundo tipo es la manipulación basada en la información; es decir, mediante la difusión de información o rumores falsos".

${ }^{8}$ Acerca de las razones que permiten justificarla naturaleza de rama del derecho tratándose del derecho económico, recomendamos al lector ver el trabajo efectuado en co-autoría por uno de los autores de esta investigación: Aimone, Enrique - SiLVA, Adolfo, La noción del derecho económico, en RDPUCV. 44 (2015), pp. 389-394.

${ }^{9}$ A propósito del origen y sentido de la denominada ética de los negocios, LópEz DE Goicoechea, Francisco, Ética y mercado de valores, en Revista de Ciencias Sociales y Humanidades 92 (2003), p. 272, precisa que: "Como nos recuerda la profesora Cortina, es en la década de los años setenta en EE.UU., cuando comienza a resonar con fuerza la businessethics o ética de los negocios, con la buena intención de penetrar en la complicada concepción de la empresa como un negocio de usar y tirar, frente a la 
Para desarrollar este tema, el presente trabajo se articula en torno a cinco partes: la primera, relacionada con el análisis del escaso marco teórico vinculado con la solución del problema planteado; la segunda, avanzando en la necesaria contribución extrajurídica, estableciendo concretamente ciertos criterios que provienen desde los fundamentos de la ética aplicada a la economía; la tercera, que se hace cargo de una nueva propuesta al modo de una solución mixta aplicada al caso; la cuarta, efectuando una aplicación concreta de la solución propuesta en la presente investigación, al analizar qué debe entenderse por principios de ética comercial bajo los términos del derecho del mercado de valores; finalmente, la quinta y última parte, quedará destinada a señalar las conclusiones del presente trabajo, dejando abierta una perspectiva para futuras investigaciones en esta línea.

II. El INSUFICIENTE MARCO TEÓRICO RELACIONADO CON LA SOLUCIÓN DEL PROBLEMA: HACIA EL ESCLARECIMIENTO DE LOS PRINCIPIOS DE LA ÉTICA COMERCIAL DESDE LOS CÓDIGOS Y LA DOCTRINA

\section{Los principios de la ética desde la fuente legal}

Teniendo presente que es el propio legislador ${ }^{10}$ quien le exige a las bolsas de valores ${ }^{11}$ que, para el desarrollo de su objeto, se preocupen de

concepción más europea de una empresa como un grupo humano que saca adelante un servicio valioso para la comunidad, como es producir bienes y servicios mediante la obtención de beneficios".

${ }^{10}$ Cabe recordar que recientemente la institucionalidad aplicable en Chile en materia de mercado de valores ha sufrido una importante modificación tras la creación de la denominada Comisión para el Mercado Financiero (CMF), la cual: "tiene entre sus objetivos principales velar por el correcto funcionamiento, desarrollo y estabilidad del mercado financiero, facilitando la participación de los agentes de mercado y promoviendo el cuidado de la fe pública; además de velar porque las personas o entidades fiscalizadas, desde su iniciación hasta el término de su liquidación, cumplan con las leyes, reglamentos, estatutos y otras disposiciones que las rijan". Disponible [en línea]: http:/www.cmfchile.cl/portal/principal/605/w3-propertyname-720. html.Fecha de consulta: 10 de noviembre de 2018.

${ }^{11}$ El término bolsa aparece por primera vez en la ciudad de Brujas (Bélgica) bajo la organización de un mercado de títulos de valores en el palacio de la familia de banqueros Van der Bursen. De conformidad a lo dispuesto en el portal institucional de la Comisión para el Mercado Financiero, las bolsas de valores: "Son las entidades donde los corredores de bolsa realizan la compra y venta de acciones y otros valores, así como las demás operaciones bursátiles que se encuentran autorizados a realizar". Cabe recordar que en Chile, y fruto de la reciente sanción aplicada por la referida autoridad a la bolsa de valores de Valparaíso (fundada en el año 1892), actualmente existen solamente dos bolsas de valores, a saber: la bolsa de valores de Santiago (fundada en el año 1893), y la bolsa electrónica de Chile (fundada en 1989). Disponible 
velar por lo que denomina como los más elevados principios de ética comercial, lo primero que se debe tratar de aclarar es qué debe entenderse por dicha expresión a la luz de lo que señalan tanto la propia LMV como sus respectivas normas complementarias, y, a partir de ello, analizar si dicho tratamiento forma parte o no de una verdadera tendencia seguida por parte del legislador chileno para responder a las exigencias derivadas de la llamada ética comercial ${ }^{12}$.

De conformidad al artículo 38 de la LMV, en concordancia con las letras b) y c) del artículo $42^{13}$ del mismo cuerpo legal, para poder cumplir con su objeto las bolsas de valores deberán prestar a sus miembros la implementación necesaria para poder realizar eficazmente -en el lugar que ella les proporcione- las transacciones de valores mediante mecanismos continuos de subasta pública y para que puedan efectuar las demás actividades de intermediación de valores que procedan en conformidad con la ley. Por su parte, el inciso primero del artículo 39 de la LMV establece una doble tare $\mathrm{a}^{14}$ para las referidas bolsas de valores al precisar que: "deberán reglamentar su actividad bursátil y la de los corredores de bolsa, vigilando su estricto cumplimiento de manera de asegurar la existencia de un mercado equitativo, competitivo, ordenado y transparente". De esta forma, surge para las bolsas de valores la obligación de no solo reglamentar su actividad y la de sus miembros o intermediarios, sino de preocuparse por vigilar el efectivo cumplimiento de dicha normativa ${ }^{15}$. A partir de este punto, puede desprenderse que la propia LMV plantea orientaciones formales para

[en línea]: http://www.cmfchile.cl/portal/principal/605/w3-propertyvalue-18541. html. Fecha de consulta: 10 de noviembre de 2018.

${ }^{12}$ Ver Fernández, Javier, La ética en los negocios (Barcelona, Ariel, 2001); GarCÍA-MarZÁ, Domingo, Ética empresarial. Del diálogo a la confianza (Madrid, Trotta, 2004); Morros, Jordi, Responsabilidad Social Corporativa (Madrid, FC Editorial, 2005) y OlCESE, Aldo, Manual de la empresa responsable y sostenible (Madrid, McGraw Hill, 2008).

${ }^{13}$ Adicionalmente, el artículo 42 de la LMV prescribe que para operar, toda bolsa de valores deberá acreditar a satisfacción de la SVS que: "b) Ha adoptado la reglamentación interna exigida por la ley; c) Tiene la capacidad necesaria para cumplir y hacer cumplir a sus miembros, las disposiciones de la LMV, sus normas complementarias y sus estatutos y demás normas internas".

${ }^{14}$ Señalamos que este deber es doble ya que, por un lado, deben reglamentar y, por otra parte, deben vigilar.

${ }^{15}$ Como señala TRUCCO, Eduardo, Las bolsas de valores y su reglamentación: inversionistas corredores de bolsa, emisores de valores (Santiago, Editorial Jurídica, 1989), p. 90: "Las bolsas de valores deben fiscalizar tanto a sus corredores como, en general, las operaciones o transacciones que se realizan en ellas. Esta obligación ha sido impuesta por la ley y, según veremos, puede verse ratificada por los estatutos y reglamentación interna de las misma bolsas". 
un tratamiento ético de la institucionalidad que reglamenta, aunque sin hacerse cargo suficientemente de la sustancialidad de dichas pautas.

Bajo los términos descritos, sin embargo, todavía no resulta posible aclarar de qué manera el ejercicio bursátil debe cumplir con aquellos principios éticos comerciales a los que los miembros e intermediarios de la bolsa deben someter su actuar para cumplir con el mandato del legislador. En otras palabras, nos enfrentamos nuevamente con una mera consideración declarativa que no va más allá en la explicitación de los contenidos de la carga axiológica que debiera alimentar aquellos principios, en vistas a suministrar una orientación que permita enfrentar y superar los conflictos éticos que puedan suscitarse en el ámbito de esta área del derecho.

Luego, si la LMV no especifica con claridad qué debe entenderse por principios éticos comerciales, cabe preguntarse si la respuesta a dicha interrogante es posible de encontrar a la luz de otras disposiciones que ordenan la facultad de autorregulación ${ }^{16}-\mathrm{y}$ a las cuales hace referencia el referido artículo 39 de la $\mathrm{LMV}$ - tal como ocurre con la existencia de los denominados códigos de ética ${ }^{17}$.

La primera sección del código de ética de la Bolsa de Comercio de Santiago regula cuál es el obrar esperado por parte del corredor de bolsa ${ }^{18}$ para

${ }^{16}$ La Ley No 21.000 del 23 de febrero de 2017, junto crear la Comisión para el Mercado Financiero, autorizó en su título VI, artículos 72 y siguientes, la creación de un Comité de Autorregulación Financiera, cuyo objeto exclusivo será dictar normas que permitan alcanzar los fines descritos en el inciso precedente y velar por su adecuado cumplimiento; establecer y acreditar el cumplimiento de estándares de idoneidad técnica y ética de los participantes del mercado de valores; resolver las diferencias o reclamos que se presenten entre sus miembros o entre éstos y sus clientes, cuando así lo solicitaren, y promover la protección de los inversionistas.

${ }^{17}$ Como recuerda García, María Nieves, cit. (n. 7), p. 175: "La regulación de los mercados de valores en los países desarrollados suele recoger criterios sobre comportamientos adecuados, además de preceptos taxativos. Así, para poder obtener autorización para ofrecer servicios de inversión, una persona debe ser considerada idónea, criterio que suele abarcar no sólo una capacitación profesional sino también una adecuación ética, por lo que las personas con antecedentes de infracciones o delitos o, en todo caso, sancionadas, pueden ver denegada su solicitud. En el caso de las sociedades, estos requisitos se suelen exigir respecto a los promotores o a los gestores".

${ }^{18}$ Según el artículo 1 del Código de Ética de la Bolsa de Comercio de Santiago, el corredor de la bolsa debe tener presente que como intermediario de valores desempeña una función en la que está comprometida la fe pública, y que, por lo mismo, requiere de una alta calidad profesional; del estricto cumplimiento de las disposiciones legales y reglamentarias que le son aplicables; de una leal sujeción a los estatutos de la institución; y de respeto por sus colegas miembros, así como de los más elevados principios de ética comercial. Por su parte, el artículo 2 del referido código de ética de la Bolsa de Comercio de Santiago, agrega que el corredor estará también obligado 
con sus colegas, clientes, o público en general ${ }^{19}$. Especial atención, ${ }^{20}$ merecen los tres primeros artículos del referido código de ética, cuando de manera genérica utiliza expresiones tales como: honradez, buena fe, honor y dignidad profesional ${ }^{21}$, y más específicamente, al exigir una vez más por parte de dichos intermediarios, el cumplimiento de los "más elevados principios de ética comercial", aunque sin mencionar, nuevamente, cuál es el contenido de los mismos.

A partir de todo lo expuesto, es posible apreciar un síntoma que se repite de manera recurrente en nuestra legislación nacional, esto es, que si bien es cierto que la LMV y sus normas complementarias exigen el cumplimiento de una serie de principios referidos a la ética comercial, dichas disposiciones no señalan ni siquiera con mediana claridad a qué se están refiriendo cuando mencionan aquellos principios ${ }^{22}$. Dicha tendencia es recurrente por parte de nuestro legislador, ya sea en relación a explicaciones genéricas relacionadas con la ética comercial o a la hora de precisar conceptos claves tales como buena fe, lealtad, honestidad, probidad, etcétera. Ahora bien, de lo que sí existe certeza es que todos aquellos conceptos - de una u otra manera- terminan por insinuar tangencialmente qué es aquello que se espera sea un comportamiento correcto bajo el actuar de los agentes del mercado. De ahí que, salvo la protección transversal a los terceros de buena fe que efectúa el código de comercio, y al anhelo permanente expresado en su mensaje por el alma del comercio de buena fe, no es mucho lo que el legislador mercantil chileno puede aportar respecto a qué es lo que envuelve aquello denominado como principios de ética comercial ${ }^{23}$.

a mantener el honor y la dignidad profesionales, siendo su deber combatir los procedimientos y prácticas bursátiles ilícitas así como la conducta moralmente censurable de quienes intervienen en el mercado de valores.

${ }_{19}$ Disponible [en línea]: http://www.bolsadesantiago.com/Normativas\%20 Bolsa\%20de\%20Comercio/4.-20C\%C3\%B3digo\%20de\%20Etica.pdf. Fecha de consulta: 10 de noviembre de 2018 .

${ }^{20}$ Señalamos que merecen especial atención, ya que la carga axiológica de la norma resulta más evidente que aquella contenida en las secciones segunda a tercera, esto es, artículo sexto al décimo.

${ }^{21}$ De conformidad al artículo 3 del Código de Ética de la Bolsa de Comercio de Santiago: "El corredor debe obrar en todo momento con honradez y buena fe. Las prácticas desleales son reprochables y no se concilian con un sano cumplimiento de las funciones de corredor de bolsa".

${ }^{22}$ Ver Salazar, Gloria - Rodríguez, María, La ética y los profesionales del mercado de valores. Investigación en cuatro ciudades de Colombia, en Cuadernos de Administración 25 (2012), 44, pp. 119-124.

${ }^{23}$ De la misma forma -pero en materia de competencia desleal- el artículo 3 de la Ley $\mathrm{N}^{\circ} 20.169$ de 2007, sin terminar de aclarar nuestra inquietud, reviste una vez más a la norma jurídica de carga axiológica al señalar que: "En general, es acto de com- 


\section{La opinión de la doctrina nacional}

Una segunda vía nos lleva a tratar de encontrar la respuesta que buscamos fuera de la normativa estricta, siguiendo la opinión que al respecto plantea la doctrina de los autores bajo nuestro contexto nacional chileno.

La primera opinión doctrinaria la entrega Silva Palavecinos al recordar que: "El código de ética comprende los principios y políticas generales que deben guiar el actuar ético-profesional de todos los empleados de la organización. El código de gobierno corporativo involucra a todos los actores, sean empleados, ejecutivos principales, directorios, comités, accionistas, clientes y proveedores"24. A partir de lo expuesto, es posible visualizar una falta de claridad conceptual que impide conocer cuáles son las diferencias y semejanzas existentes entre los denominados códigos de conducta, códigos éticos y códigos de gobierno corporativo. Todo lo anterior, termina por considerar como semejantes a instrumentos que si bien provienen de la misma raíz autorregulatoria gozan de diversa especificidad.

Una segunda postura dentro de la doctrina chilena es aquella que asimila ética comercial con el concepto de buena fe objetiva. Esa es la postura de Aimone, quien a propósito del artículo 43 letra a) de la LMV nos enseña que: "En efecto, todos nosotros, y no solo como agentes de un mercado, debemos comportarnos conforme a las reglas éticas. Pero lo que se exige en esta materia es comportarse conforme a los más elevados principios de ética comercial. La ética comercial, en buenas cuentas, es la que informa los artículos 1545 y 1546 del C. Civil. Pero lo que con el art. 43 c) se exige es un máximo al respecto" 25 .

A partir de la opinión doctrinaria recién referida, se logra apreciar que también aquí nos encontramos con escasas aproximaciones genéricas que no se hacen cargo del planteamiento y de la consistencia de la argumentación ética propiamente tal. Por todo lo anterior, creemos que resulta necesario avanzar en la comprensión de los principios de la ética comercial recurriendo a otras disciplinas que confluyan conceptualmente en el esclarecimiento de los contenidos, con el objeto de evitar confusiones

petencia desleal toda conducta contraria a la buena fe o a las buenas costumbres que, por medios ilegitimos, persiga desviar clientela de un agente del mercado". La misma regla cabrá aplicar, por ejemplo, tratándose de los bullados casos de colusión a los cuales hace mención el artículo 3 letra a) del Decreto Ley № 211 de 1973, ya que al final de cuentas, termina haciendo referencia también a prácticas deshonestas y contrarias a la buena fe.

${ }^{24}$ SILVA, Berta, Metodología de la OCDE para la evaluación de principios de Gobiernos Corporativos (Santiago, Thomson Reuters, 2011), p. 56.

${ }^{25}$ Aimone, Enrique, Actividades económicas reguladas. Teoría y Casos (Valparaíso, Thomson Reuters, 2014), pp. 92-93. 
terminológicas que enturbien la comprensión de los distintos códigos en el ámbito de sus materias.

\section{LA NECESARIA CONTRIBUCIÓN EXTRAJURÍDICA: LOS CRITERIOS QUE} PROVIENEN DESDE LOS FUNDAMENTOS DE LA ÉTICA APLICADA A LA ECONOMÍA

\section{La insuficiencia del mero análisis jurídico}

Teniendo presente el marco señalado, y frente a la imposibilidad de poder encontrar una respuesta que satisfaga íntegramente la interrogante planteada desde el inicio de esta investigación, cabe preguntarnos si resulta posible intentar buscar una solución desde una vía alternativa y complementaria al ámbito jurídico. En otras palabras, la aplicación de principios de ética comercial y el cumplimiento de conductas adecuadas, ¿resulta exigible solamente desde y para el ámbito legal, o bien, su respuesta debiera obtenerse a partir de las consideraciones de otras ciencias sociales, como la filosofía y la economía? si es así, dichas miradas nos obligarán a considerar y ponderar que deben confluir otros elementos de análisis que incorporen razonamientos complementarios que contribuyan a definir la regulación de la conducta humana. Como nos recuerda Salazar y Rodríguez: "Dichos comportamientos están basados en valores morales fundamentales como honestidad, justicia, responsabilidad, respeto y solidaridad"26, pues, según Cortina: "si el ejercicio de la actividad profesional exige excelencia, entonces el derecho es insuficiente: es preciso forjar el 'êthos', el carácter de la actividad, que se forma con valores, principios y virtudes, no con el mero seguimiento de leyes" 27 -

Efectivamente, si de lo que se trata es de encontrar una vía argumentativa que aporte al perfeccionamiento del talante o el modo de ser de la persona-que es lo propio de la reflexión ética- el derecho debe verse auxiliado por la ética. Con ello evitamos caer en lo que uno de nosotros ha llamado -siguiendo a Diego Gracia- la "falacia del juridicismo reduccionista"28, que consiste en la pretensión de dejar que sea la norma o una aproximación dogmática la que se extienda hacia el intento de explicación de una realidad que no puede abordar por sí misma, sin recurrir a otra disciplina. En este caso la ética. Esta consideración es la que nos invita a centrar los objetivos de esta investigación desde una mirada antropológico-ética que oriente las decisiones que se toman en el mercado. Y es la misma razón

\footnotetext{
${ }^{26}$ Salazar, Gloria - RodríGuez, María, cit. (n. 22), p. 124.

${ }^{27}$ Cortina, Adela, La dimensión pública de las éticas aplicadas, en Revista Iberoamericana de Educación 29 (2002), p. 48.

${ }^{28}$ Faúndez Allier, Juan Pablo, La bioética de Diego Gracia (Madrid, Triacastela, 2014), p. 379.
} 
que, como veremos más adelante, justifica la necesidad de una respuesta holística para nuestra postura. De la misma manera, es dicha consideración la que fundamenta algunas de las tesis económicas que reclaman la presencia de lo ético ${ }^{29}$, ya que desde el momento en que la actuación del ser humano considera su interrelación con otros elementos en búsqueda de objetivos materiales e inmateriales, la reflexión económica se torna indefectiblemente un estudio acerca de la eticidad humana. Y desde allí, en una línea correlativa, como ilustra Menchaca, la ética económica deberá analizar rigurosamente los hechos con el objeto de que sus conclusiones no sean erróneas ${ }^{30}$.

En consecuencia, y a partir de lo expuesto, es posible apreciar que bajo la exclusiva perspectiva económica, el panorama no resulta más auspicioso que el analizado en el mero ámbito jurídico. El prisma individual de la ciencia económica también resulta insuficiente para dar una respuesta que se haga cargo efectivamente de los principios de ética comercial ${ }^{31}$. Por ello

${ }^{29} \mathrm{Al}$ respecto, cabe recordar que la ética según GarCía, María Nieves, cit. (n. 7), p. 164-165, surge como: "La parte de la filosofía que trata de los actos morales, que son los actos humanos libres y deliberados (regulados por la regula morum). La ética se refiere a los principios morales que, a su vez, se refieren a la conducta que está bien y a la que está mal, o a la bondad o maldad del carácter humano".

${ }^{30}$ Para clarificar esta idea, MenchacA, Tomás, La ética Económica: sus aspectos fundamentales, en RDUA. 3 (1992), 1-2, p. 40, especifica que: "Es en este sentido que podemos decir que la teoría económica no se preocupa de analizar la bondad o maldad de las acciones humanas. Tanto la economía como la ética estudian el acto humano, libre y racional, pero la diferencia es que la ética lo estudia desde el punto de vista de la bondad o maldad de las acciones, en cambio la economía no estudia sino cómo actúa el hombre. Es por ello que podemos decir que los postulados científicos de la economía son correctos o equivocados, completos o incompletos, pero no buenos o malos, ni liberales, ni keynesianos. Lo anterior no pretende desconocer, sino aclarar, la íntima relación existente entre la ética y la economía, pues el pensamiento económico sólo puede ser realizado por hombres, que valoran y juzgan moralmente. Es por ello común que los economistas realicen juicios éticos, pero al hacerlo debieran valerse de las enseñanzas de la ética, ya que ningún análisis puramente cuantitativo (como el económico) puede proporcionarnos un criterio cualitativo (como es el de la ética)".

${ }^{31}$ La ciencia económica es incapaz para dar una respuesta integral, ya que resulta necesaria una dosis de ética en los sistemas económicos para tratar de dar solución al problema que subyace tras la elección entre equidad y eficiencia. En este sentido, como explicita GuZMán, Joaquín, El rol de la ética en la ciencia económica, en Revista de Economía 823 (2005), p. 18: "No es de extrañar, por consiguiente, que en la actualidad existan dos esferas de conocimiento de difícil relación, no sólo para el actual hombre de la calle sino también para la mayor parte de los economistas de nuestro tiempo. Sin embargo, el hecho de que se haya perdido prácticamente esa raíz moral en los estudios e investigaciones económicas no significa, ni mucho menos, que la 
es necesario profundizar en la comprensión de que desde sí misma aporta la filosofía.

\section{Base antropológica: el origen para una respuesta multidisciplinaria de naturaleza social}

En consecuencia, si la premisa es la mirada antropológico-ética, la comprensión de la doctrina jurídica aplicada a esta materia debería considerar la naturaleza social y el fundamento filosófico que se hayan tanto tras la economía en general, como del modelo capitalista en particular. Lo anterior resulta especialmente importante si consideramos que la gran mayoría de los manuales de la disciplina terminan por situar el nacimiento de la economía como ciencia en el año 1776, fecha en la que Adam Smith publica su obra Investigación sobre la naturaleza y causas de la riqueza de las naciones ${ }^{32}$. Lo que no siempre nos recuerda la historia es que Smith, antes de ser economista, fue filósofo moral ${ }^{33}$, y dentro de

ciencia económica deba carecer de base ética. Posiblemente, en esa carencia forzada a lo largo de los dos últimos siglos, puedan radicar algunas de las claves fundamentales para explicar la impotencia de la economía en ámbitos tan cruciales como las desigualdades crecientes, el hipo desarrollo permanente, las bolsas de pobreza, las migraciones clandestinas, el paulatino deterioro del medio ambiente, el desempleo masivo y la precariedad masiva del empleo, la crisis del estado del bienestar, etcétera. El funcionamiento del sistema económico. A pesar del mencionado distanciamiento entre los campos de la ética y de la economía, no por ello hay que olvidar que, en la práctica, cualquier sistema económico necesita una mínima dosis de ética para su funcionamiento".

${ }^{32}$ Ver SMITH, Adam, Investigaciones sobre la naturaleza y causas de la riqueza de las naciones (Madrid, Tecnos, 2009).

${ }^{33}$ Como acertadamente nos recuerda GuZMán, Joaquín, cit. (n. 31), p. 18, uno de los mayores aportes de Smith fue la inserción de lo que hoy denominamos economía dentro del circuito académico y su elevación a rango universitario, ya que: "si bien la obra de Adam Smith significó una sistematización de los conocimientos económicos de la época y una contribución fundamental en temas concretos, como la división del trabajo y la teoría del valor, lo que probablemente tuvo más repercusión para la posteridad fue la elevación de los estudios económicos a rango universitario. El ilustre escocés no era académicamente un economista, por la simple razón de que aún no existía tal especialidad en la universidad. Fue a partir de su obra, cuando las enseñanzas de la economía adquieren un corpus autónomo dentro de las materias científicas universitarias. De ahí también la aureola de "padre» de la ciencia económica con la que ha pasado a la historia. No obstante, antes que economista, Adam Smith era filósofo moralista. En la Universidad de Glasglow era catedrático de filosofía moral y su obra intelectual está impregnada de una notable inquietud por los criterios éticos en el comportamiento económico, lo que viene a significar la prolongación y consolidación del enfoque aristotélico frente al de Kautilya. Sin embargo, a partir de los más directos sucesores de Smith, en la misma Gran Bretaña 
dicho ámbito de conocimientos, este texto fue precedido el año 1759 por la Teoría de los sentimientos morales ${ }^{34}$. De ahí que solo bajo una mirada que incluya el estudio de las dos obras señaladas, es que se podrá contar con una visión integral del pensamiento de este autor, y en cuya virtud la economía pasa a constituirse en una actividad capaz de generar felicidad a través del respeto por el trabajo, la dignidad del trabajador, y la libertad económica ${ }^{35}$. Ciertos tipos de valoración que, aun cuando no estuviese desarrollada la teoría material de valores iniciada por Max Scheler, daban cuenta ya de percepciones emotivistas clasificables en el ámbito del placer generado por las acciones. Los presupuestos utilitaristas profundizados por Jeremy Bentham y, especialmente, John Stuart Mill, precisarán, con posterioridad, este enfoque.

En consecuencia, si el objeto de estudio tanto de la economía como de la ética y el derecho es el comportamiento humano, con sus particulares distinciones, y si a ello sumamos que la economía en tanto área del conocimiento encuentra en su base una consideración moral que le obliga a fijar la existencia de ciertos límites en su actuar, la relación que a lo largo del presente estudio planteamos como necesaria comienza progresivamente a tomar sentido. De este modo, si a partir de la obra de Smith la economía pasa a ser considerada como ciencia, esta consideración debiese privilegiar y considerar como norte una mirada antropológica que, por tanto, habría de reconocer la pertinencia de una naturaleza social antes que una mirada impersonal más propia de las denominadas ciencias exactas. Ahí pareciera que se encuentra uno de los factores de origen para lo que hoy conocemos como conductas poco éticas en el marco del mercado de valores y en el

y en Francia (D. Ricardo, T. Malthus, J. Bentham, J. B. Say), se inició a lo largo del siglo XIX un paulatino distanciamiento entre los ámbitos de la ética y de la economía que ha llegado hasta nuestros días. La ya mencionada obsesión por equiparar los métodos de la economía a los de las ciencias naturales, en busca de una desmesurada exactitud numérica (que en muchos casos se ha mostrado irreal) y la identificación del concepto de utilidad al de bienestar e incluso al de felicidad en el género humano, ha significado de facto dos poderosos motores en ese largo y progresivo proceso de divorcio entre lo ético y lo económico".

${ }^{34}$ Ver SMITH, Adam, Teoría de los sentimientos morales (Madrid, Alianza, 2004).

${ }^{35}$ Esta libertad debía ser guiada por la prevalencia de las virtudes de la justicia y la beneficencia, amparada por la simpatía y controlada por el juicio del observador imparcial, que no es más que la voz de nuestra propia conciencia. A propósito de esta relación entre economía y filosofía moral, G. Salazar y M. Rodríguez, nos recuerdan que Adam Smith proponía que los conflictos de interés derivados de la competencia económica se debían resolver autónomamente mediante el apoyo de la capacidad natural de simpatía y conforme a los dictámenes de la justicia, todo lo cual llevaría al bienestar social a través de la búsqueda del propio interés en comunidad. Ver SALAZAR, Gloria - RodríGUEZ, María, cit. (n. 22), p. 121. 
modelo capitalista en general. Es decir, el olvido de la consideración social que desde sus inicios adoptó la ciencia económica. Como nos recuerda Sierra González: "La economía desde el siglo XVIII ha tratado de convertirse en una ciencia, es decir, en un conocimiento riguroso, analítico y comprobable de cómo realizar en mejor forma las actividades productivas, distributivas y de consumo. La ciencia económica moderna intenta estudiar y medir los fenómenos económicos, en forma semejante a como lo suelen hacer las ciencias naturales. ¿Qué estudia la ciencia económica? La manera como las personas y los pueblos satisfacemos nuestras necesidades, produciendo mediante nuestro trabajo bienes y servicios con recursos escasos. Frente a estas pretensiones teóricas que se presentan como nacidas de una neutralidad valorativa surge la fuerza de la realidad. La economía, en tanto ingeniería con pretensión de ciencia exacta, comprendida como un ejercicio de lógica matemática, encuentra sus límites"36.

Lo anterior se vuelve especialmente interesante al recordar que tanto en el pensamiento de Smith como en el propio modelo capitalista se aprecia una marcada influencia del individualismo y del utilitarismo. Por la misma razón, es que desde el momento en el que la ciencia económica se comienza a alejar de su concepción antropológica e intenta migrar hacia una concepción exacta más propia de las ciencias básicas, el grado de tolerancia o parámetro bajo el cual se reconocen, regulan y juzgan las conductas que pudieran ser consideradas como contrarias a la buena fe, la lealtad y/o la ética, se vuelve también más laxo. De hecho, basta pensar: ¿qué puede resultar más rentable que la realización a corto plazo de una conducta incorrecta o poco ética?, o bien, ¿cuántas veces nos hemos enfrentado a situaciones en las cuales el individualismo y el utilitarismo propios del modelo capitalista nos indican que el único camino viable para obtener los resultados esperados o proyectados es la realización de conductas reñidas con la ética?, o peor aún, ¿cuántas veces la propia academia ha instado a sus alumnos a colocar el énfasis en los números antes que en las personas?

\section{Criterio objetivo y valores éticos}

Con todos estos elementos de análisis, ¿cuáles podrían ser las conductas consideradas como constitutivas de los principios de ética comercial a los cuales hace referencia la LMV y el resto de las normas complementarias de nuestra legislación? Por otro lado, si existen tales principios de ética comer-

${ }^{36}$ Sierra, Ángela, Mercado y valores éticos en Jornadas de formación de la comisión general de justicia y paz. Disponible [en línea]: http://justiciaypaz.dominicos.org/ kit_upload/PDF/jyp/Realidades\%20Sociales/MercadosEtica.pdf. 
cial, ¿`cuál es la función que, al respecto, debe cumplir tanto el derecho del mercado en general, como el derecho del mercado de valores en particular?

Acerca de la primera inquietud, nuestra tesis es que las conductas que puedan ser consideradas como contrarias a los principios de ética comercial, coinciden con todas aquellas actuaciones u omisiones que puedan ser clasificadas como contrarias a los "valores-éticos" para la actividad mercantil, es decir, aquellos que logran superar el nivel meramente utilitario ${ }^{37}$ de "valores-precio" 38 . En otras palabras, disvalores que confrontan a sus valores opuestos en el esquema dicotómico en el que se desarrollan los valores.

De este modo, bajo nuestra postura, los denominados principios de ética comercial podrían entenderse a la luz de la denominada ética material de los valores, siendo éstos realidades objetivas cuya percepción inicial estaría encargada a la percepción emotiva pero en un espectro incomparablemente superior al planteado por la propuesta utilitarista-consecuencialista de Hobbes, Bentham y Mill. Esta escuela de línea anglosajona, si bien se basa en la emotividad como fuente de orientación ética, se proyecta en un reduccionismo emocional que no supera los criterios de maximización de la utilidad beneficiosa, relacionada con el placer, como baremo de catalogación de actos moralmente correctos.

En una proyección de mucho mayor consistencia filosófica se alza la ética material de valores. Los presupuestos de esta propuesta podemos relacionarlos incipientemente con la obra de R. Lotze (1817-1881), quien en Microcosmos establece la distinción entre un reino del ser de tipo objetivo y un reino de los valores, señalado por las preferencias de los sujetos humanos, poseedores de un órgano de percepción relacionado con el sentimiento valorativo (Wertgefühl). Posteriormente, y en un escenario de anticipación directo a la propuesta de M. Scheler, F. Brentano (1838-1917) retrotrae en Sobre el origen del conocimiento moral (1889) la conciencia moral a experiencias psicológicas precategoriales desde las que posteriormente se podrán reconocer conceptos morales, junto a actos de valoración

${ }^{37}$ Cabe recordar que esta frase forma parte de la aplicación de la economía al campo de las ciencias naturales, iniciada a partir del siglo XIX, y que incluso llegó a sostener que en la ciencia puramente física no existe tentación de observar el aspecto ético, véase en Mill, John Stuart, El utilitarismo (Madrid, Alianza Editorial, 1984). Con ello se olvidaba que los elementos subjetivos y los juicios de valor siempre están presentes en todos los ámbitos de las ciencias sociales y, por ello, también en la ciencia económica, ver GuZMán, Joaquín, cit. (n. 31).

${ }^{38}$ En dicho sentido, los principios de la ética comercial debiesen ser capaces de dar respuesta y superar el viejo refrán anglosajón en cuya virtud Business a re business (los negocios son los negocios), y por el cual se da a entender-ya desde tiempos de la Inglaterra victoriana- que la obtención de un mayor precio puede incluso llegar hacer prescindir de cualquier consideración ética. 
y preferencia. Este planteamiento hay que vincularlo en el mismo autor con el redescubrimiento de la intencionalidad, que Brentano menciona como el modo de comprender el acaecimiento de los actos de conciencia que permite distinguir los actos psíquicos de los hechos que acaecen en la naturaleza. Siguiendo en esta línea, A. Meinong, Ch. Ehrenfels y toda la Escuela de Graz definirán valor como una cualidad que se reconoce en los objetos, instancia que genera los sentimientos de aprecio y estima en los sujetos que realizan el acto de percepción, siendo M. Scheler ${ }^{39}$, sus discípulos y seguidores ${ }^{40}$ los que terminarían por establecer y desarrollar esta escuela ética.

Aunque no puedan verse físicamente, los valores sí pueden percibirse gracias a la capacidad estimativa, con lo que se apunta a una habilidad independiente que debe ser desarrollada: la educación estimativa de los valores. Así como es necesario formar a las personas para conocer e interpretar los hechos que enfrentamos en la vida cotidiana, es menester, de igual forma, manejar, distinguir y jerarquizar los valores, mediante el proceso educativo que permite ordenarlos según diversos esquemas de prelación. No reconocer esto nos llevaría a permanecer en un mero positivismo, o en una interpretación errada de la realidad, entre ellas la económica, por la que no se distinguirían valores de distinto nivel, por ejemplo, intrínsecos o instrumentales. Para ello es útil contar no solo con la necesaria claridad comprensiva, sino también con una adecuada educación de los sentimientos y las emociones, ya que es a raíz de su aplicación que se impulsan los procesos de valoración de la realidad. Todos estos elementos deben tenerse presente en el momento que se quiera llevar adelante, desde el punto de vista de la realización moral, el proyecto cultural de cualquier actividad comercial, ya que las personas, sus interrelaciones y las cosas en general, son necesariamente depósito de valores, siendo tarea de la axiología explicitar cuáles son esas cualidades y cómo podemos profundizar en nuestra capacidad de percepción de las mismas.

Este proceso de valoración, en el que la comprensión del sentir aporta la materia a la inteligencia, denota a esta última como rasgo biológico y fenotípico que posibilita la adaptación del medio, mediante la valoración de la realidad. Por ello el ser humano construye esbozos de posibilidades que verifica permanentemente mediante la experiencia, realizando tanteos proyectivos que se interpretan emotivamente gracias a la valoración que

\footnotetext{
${ }^{39}$ Ver Scheler, Max, Ética (Madrid, Caparrós, 2001).

${ }^{40}$ Téngase presente a Dietrich Von Hildebrand, Nicolai Hartmann, José Ortega y Gasset, Xavier Zubiri, Adela Cortina o Diego Gracia, entre los principales autores que han traído la reflexión sobre los valores hasta el presente, los tres últimos, especialmente en el contexto hispánico.
} 
se hace de ella. Allí es donde radica el problema de la ética, desde la perspectiva axiológica, porque es el momento que dice relación con lo que se debe hacer o no en el futuro que se va abriendo para cada ser humano como posibilidad de realización. En esto consiste el paso del esbozo de posibilidades a la experiencia moral propiamente tal, el aterrizaje que significa abrir las alternativas que permiten una efectiva toma de decisiones que se consolidan por la voluntad. A través de estas instancias se puede notar cómo la realidad se actualiza mediante cada una de las facultades superiores humanas -intelectiva, emocional y volitiva- expresándose de forma conjunta que el intelecto se proyecta en función de un fin específico, a lo que se une íntimamente una valoración concreta del hecho realizada por las emociones. Los hechos están a la espera de la valoración que el ser humano hace en relación a ellos, lo que aporta un nuevo matiz en el análisis del fenómeno moral. Por ello los hechos y los valores se muestran siempre unidos, dado que no puede haber hechos humanos que no cuenten con una valoración respectiva.

Lo anterior permite considerar que el acto de valoración se realiza mediante una configuración compleja que se nutre de aspectos históricos, intelectuales, físicos y emocionales, y que desencadenan consecuencias prácticas. Todos estos factores conformarán la cultura, entendida como el «depósito de valor» que posibilita la proyección humana en tanto que elaboración moral del ajustamiento del medio. El perfil de la teoría axiológica objetiva -o del valor que se reconoce de distintas realidades- intenta explicar que hay una parte de la realidad en la que es posible reconocer una ordenación legal que constituye el fundamento de la ética. Gracias a esta objetividad, que se comprende intuitivamente, es posible encontrar sentido a las decisiones que se vinculan con las acciones humanas. Scheler plantea de este modo una ética material que se alza frente a la propuesta formal kantiana, llevando adelante un diálogo crítico que desplegó a través de su Ética. Por ello dice Scheler que aunque las cosas tengan propiedades que motivan la realización de las acciones, eso no significa que éstas se hagan necesariamente en función de una motivación placentera o hedonista en concreto, que es la alternativa que justamente criticaría Kant. Los valores son ese rasgo a priori que se atribuye a las cosas, que no se obtiene de forma empírica, como el placer, fundamentando una teoría ética en una perspectiva totalmente distinta a como lo hace el filósofo prusiano. Aun cuando los argumentos de Scheler no tienen como principal objetivo confrontar las formulaciones kantianas, sino más bien impugnar un relativismo presente en un planteamiento subjetivista de la teoría de los valores, gracias a la fenomenología aplica la intuición de las esencias para fijar la base que sirve para establecer una ley utilizable en todos los casos. Plantea así una 
formulación apriorística que hace frente al subjetivismo empírico. Por tanto, hay leyes que se dan de modo a priori mostrando cómo se pueden descubrir desde la capacidad intuitiva de los seres humanos.

Llegados a este punto, es posible afirmar que una ética axiológica, en tanto modelo de una ética aplicada que quiera desarrollarse en la actualidad, debe dar cuenta de un criterio objetivo y externo a la norma jurídica que permitiría reconocer qué debe entenderse bajo la noción de principios de ética comercial. Principios que se tornan operativos desde el reconocimiento de valores objetivos. No podría ser de otra manera, desde que las personas, sus interrelaciones y las cosas en general -bajo la perspectiva señalada- son necesariamente depósito de valores que deben ser explicitados por la axiología como disciplina, mostrando en qué consisten las notas de cada uno de los valores y cómo podemos profundizar en nuestra capacidad de percepción de las mismas. Una vez que esa distinción axiológica ha llegado a su mayor grado de explicitación, desde los mismos valores que se reconocen como soporte, surgen deberes de actuación o de aplicación de hábitos operativos, que es el momento en el que entra a jugar la aplicación de la ética, estrictamente hablando ${ }^{41}$. Puesto que uno es el momento de valoración que hacemos de los hechos (axiología), y otro, el que surge con el deber que se origina ante la necesidad de realizar efectivamente los valores para no caer en la alternativa binaria: la generación de disvalores. Una vez que se ha realizado el juicio de aplicación del valor, ha de llevarse a cabo el acto de deliberación que se relaciona con el deber de actuación, que se expresará prescriptivamente a través de un mandato o una orden imperativa que pretende realizar efectivamente los valores que se proponen: v. gr., se espera que un agente del comercio deje de realizar los disvalores de improvisación, indignidad, egoísmo, irresponsabilidad, desconfianza y descompromiso (correlativos a los respectivos valores en la jerarquía), porque con ello se falta a la cultura que se intenta construir a través del desarrollo de los valores que se busca cultivar por parte de los distintos actores al interior de la actividad comercial. Con este proceder, que comienza desde la ponderación de los hechos, el juzgamiento axiológico y la aplicación de deberes de actuación, se va asegurando progresivamente la realización efectiva de hábitos que encaminan hacia la concreción del bien moral aplicado a la respectiva actividad mercantil.

Lo interesante del planteamiento de la ética material de valores es que, al igual que la fundamentación utilitarista sostendría, los valores son cualidades que se aprecian inicialmente a través de los estados de ánimo, aunque ampliando esta percepción, en el caso de la axiología, más allá del

${ }^{41}$ Faúndez Allier, Juan Pablo, cit. (n. 28), p. 373. 
reducido sistema de autorreferencialidad egoísta, propio del utilitarismo, corriente de la ética tan cercana a la economía. Por ello, si bien las éticas utilitarista y axiológica comparten esa nota emotiva de entrada, es la axiológica la que responde de manera más consistente a la distinción no sólo del valor de utilidad placentera, sino a una amplia gama que se incardina en diversas jerarquías: desde la sacralidad hasta la utilidad. De este modo, y dado que la valoración ética nos envuelve permanentemente, la irrupción del valor, como categoría ética, lleva a la necesidad de reconocer el ejercicio de la moral también al interior de la actividad comercial, generando posteriormente deberes de actuación.

En consideración a la aplicación del método en relación a nuestra postura, la actuación responsable en el contexto comercial se iniciará con el hecho de tener que asumir que para llevar adelante un proceso idóneo de decisión ética es necesaria una adecuada deliberación en torno a los hechos, seguida de una idónea deliberación vinculada con los valores que se han de desarrollar para que la acción sea efectivamente buena desde el punto de vista ético, dando paso finalmente a la obligación de deber, por la que se concretará la realización efectiva de los valores que se considera necesario ejercer ante la problemática que se estuviera enfrentando. Todo lo anterior, teniendo presente la posible presencia de consecuencias negativas que es necesario evitar. Para establecer esta situación se deben seguir los tres pasos procedimentales ya descritos: hechos, valores y deberes, que son los que servirán para una ponderación que no llevará necesariamente a respuestas verdaderas o falsas de forma categórica, sino más bien a las que resulten prudentes o virtuosas en el contexto en el que se quiera ir acumulando los valores que van dando forma a la cultura que se ha de desarrollar en torno a una determinada actividad mercantil. Esto porque la ética no es una disciplina que conduzca a conclusiones apodícticas, debiéndose buscar en el ámbito de la moral soluciones no exclusivas que señalen qué se debe hacer al ponderar los hechos, los valores, los deberes y las consecuencias que se pueden suscitar con la realización de las acciones. Por ello es importante llevar a cabo una aproximación metodológica de los problemas, ya que de este modo es posible lograr altos estándares de excelencia en la decisión ética, evitando la prisa de caer en la falacia del juridicismo reduccionista.

Dado que desde una inicial estimación emotiva se sigue un proceso intelectivo de distinción jerárquica de valores, la comprensión de una mera emocionalidad ciega es superada por la claridad del sentido que surge desde una comprensión constructivista de línea zubiriana. Con Zubiri es posible percibir que el sentimiento se manifiesta como el afecto de la realidad fundado por una intelección formal que tonifica al ser humano 
y que suscita de este una determinada respuesta volitiva. De este modo, desde la comprensión zubiriana de la inteligencia sentiente como el sentimiento afectante y la voluntad tendente se manifestará una forma intelectiva, emocional y volitiva por la que se da la realidad. Así será posible obtener una distinción fundamental en relación al carácter diverso que posee la teoría zubiriana en comparación con el objetivismo y el subjetivismo axiológico. Se trata de una teoría construccionista de la valoración por la que los valores se construyen desde las posibilidades efectivas que permite la realidad, porque el sentido corresponde a ésta, enriqueciéndola en tanto que le concede su ser más propio. Así es como se manifiesta el bien de la realidad, soportando valores que tienen un sentido. Los valores son construidos como "cosas-sentido» que justamente cobran este último en el curso de la vida humana, puesto que significan algo valioso para el ser humano. Para Zubiri, por tanto, la estimación de los valores no surge como fruto de la intuición, sino como consecuencia de la construcción que se hace a partir de las "cosas-sentido". Así, la labor constructiva de los valores se realiza desde unos datos originarios que consisten en las sensaciones por las que la realidad se hace presente. Y entre las sensaciones se encuentran, obviamente, los sentimientos sensibles.

Así como Rawls o Habermas han desarrollado teorías procedimentalistas que han perseguido un objetivo universalista, actualmente la teoría axiológica debiera reconocer una superación del intuicionismo no recayendo en un nuevo objetivismo, ni en un relativismo, sino yendo tras un intersubjetivismo axiológico. Desde esta perspectiva, no habría otra forma de buscar un acuerdo valorativo, dado que la mera apreciación de lo en sí resultaría insuficiente si no se explicara dentro de un contexto que estaría marcado por un cierto sentido o dirección constructivista. Con ello se percibe a los valores como rasgos que se dicen de una cosa en un contexto dinámico que se capta emocionalmente, y desde el cual se sopesan intelectualmente las consecuencias que se relacionan con la decisión a tomar. Todo ello en un cuadro de deliberación desarrollado ya individualmente o por un conjunto de personas. Desde allí se tomarán decisiones que surgirán como fruto de una adecuada jerarquización valorativa. De este modo, el proceso de construcción axiológica surge desde una perspectiva colectiva y de tipo relacional que muestra la necesidad de conservar la clasificación antes mencionada, aunque dotándola de una connotación constructivista e intersubjetiva.

Dado que la actividad comercial debe suscitar ciertos comportamientos basados en valores y evitar acciones contrarias que se sostengan en disvalores, la moral que se pretende desarrollar en el ejercicio de las distintas funciones de los sujetos de la actividad mercantil implica asumir hábitos 
operativos que llevan hacia obligaciones de actuación que necesariamente deben cumplirse para que los valores señalados efectivamente se realicen. Esto surge desde una adecuada y reiterada inducción que lleve a conocer, manejar y finalmente internalizar los valores entre los correspondientes sujetos. Desde el reconocimiento de la etapa axiológica, con la suscitación del deber se puede generar un sistema que llegue incluso a sancionar los incumplimientos culpables. El deber de aplicar valores es el momento en el que se promueve no caer en el disvalor que lo pone en riesgo, materializando la decisión al optarse por un valor concreto que se opone al disvalor respectivo. Cuando eso ocurre, es el sistema orquestado de quienes participan en la actividad comercial el que se ve beneficiado, ya que de manera efectiva se decide éticamente en orden al bien que representan los valores. Con ello se va concretando la consolidación efectiva de valores tan importantes para el ámbito comercial como lo son, entre otros, la confianza y el compromiso entre los distintos tipos de sujetos comerciales, lo cual permite generar interrelaciones cargadas de valor en la respectiva actividad mercantil.

De este modo, no cultivar un valor implica caer en un disvalor: es decir, si no se trabaja la confianza se caerá en la desconfianza; o si no se afianza el compromiso, se derivará en la falta de compromiso. En otras palabras, bajo el método esbozado no hay salidas intermedias, ya que la distinción axiológica no lo permite. Ello hace que el deber de realizar valores sea insoslayable, aunque libre. En efecto, es precisamente por la libertad que se puede llegar a conformar finalmente un sistema de deberes que se justifica desde la axiología y que resulta ser fácilmente asimilable por los distintos estamentos de la actividad comercial. Entonces pueden surgir las sanciones ante la falta de cumplimiento de deberes, que se justifican porque nadie que ha sido iniciado axiológicamente al interior de la respectiva actividad mercantil debiese realizar disvalores que lo lleven a resultados indeseados. Son actitudes que no se comprenden, y que si se realizan se sancionan. Por la misma razón, es que todos los miembros del comercio debiesen tratar de construir en el mismo sentido, y en consecuencia, mayor debiese ser también su compromiso.

\section{LA PROPUESTA: UNA SOLUCIÓN MIXTA}

Llegados a este punto, y una vez analizadas de manera separada las diferentes alternativas de solución, cabe preguntarse si se encuentra resuelto aquello que debe entenderse por principios de ética comercial, y en caso afirmativo, si dicha solución responde a una respuesta aislada o conjunta de las tres disciplinas de naturaleza social sometidas a estudio. 
Tal como hemos venido esbozando a lo largo del presente trabajo, nuestra propuesta ${ }^{42}$ parte de la base del establecimiento de una mirada holística e integradora que permita dar una respuesta conjunta a la interrogante planteada a partir del aporte complementario de las esferas jurídica, económica y filosófica. En dicho sentido, nuestra posición busca armonizar elementos que mirados aisladamente no permiten entregar una respuesta satisfactoria a nuestra interrogante.

\section{Lo económico y lo ético}

En primer lugar, cabe referirse al aporte que la ciencia económica pueda efectuar para nuestra propuesta. Al respecto, conviene señalar que éste implica un marcado respeto por una mirada antropológica de dicha ciencia social, y que, por tanto, priorice una búsqueda de resultados basándose en la importancia del ser humano y de su comportamiento en sociedad. En efecto, una mirada social de la economía y, por consiguiente, de los modelos bajo los cuales se aplica, debiese privilegiar y preferir una concepción que coloque y considere a la persona antes que el número, y a la responsabilidad social antes que el utilitarismo individual ${ }^{43}$. De ahí también, lo acertado

${ }^{42}$ Una opinión diversa a la planteada en este trabajo, es la que propone Fernández, para quien la solución sí se puede encontrar en el derecho sin necesidad de tener que recurrir a otras ciencias sociales, en tanto plantea que: "Si la dimensión subjetiva de la ética sólo se atiene a la conciencia individual y debe limitarse por tanto -como aquí se sostiene- a inspirar el comportamiento de los operadores económicos, sin especificidad alguna, resulta claro -y éste ha sido el hilo conductor de toda la exposición- que lo que el mundo de los negocios necesita no es una valoración moral sino una valoración exclusivamente jurídica -y en consecuencia sancionatoria- del comportamiento de sus miembros. Son las normas jurídicas -expresión de los valores y también de los principios éticos compartidos por la sociedad y reflejo a su vez de las necesidades colectivas- el instrumento regulador por excelencia de las actividades mercantiles y financieras. Las reformas legislativas y la labor interpretativa de los tribunales velarán en todo caso por una correcta adaptación de las mismas a los datos de una realidad económica, que cambia constantemente de reglas y comportamientos, productos e intermediarios. Afirmación que encuentra hoy su mejor ejemplo en la tutela del medio ambiente o en la regulación de los mercados financieros, sectores ambos en los que los vínculos y deberes establecidos para atemperar la maximización del beneficio empresarial han terminado por depender mucho más de las reglamentaciones públicas que de una supuesta contención moral de los propios operadores” (FERnÁndez, Luis, cit. (n.1)).

${ }^{43}$ A mayor abundamiento, creemos que una mirada social del mercado es lo que mejor se condice con las legítimas pretensiones de los diferentes grupos de interés de inicios del siglo XXI. De lo contrario, pensamos que la propia naturaleza humana llevada muchas veces por la mano del selfish sistem, o sistema de egoísmo -en palabras de Hobbes- se encargaría de encontrar la manera de obtener el mayor beneficio in- 
que resulta la apreciación del Premio Nobel de Economía del año 1998, Amartya Sen, al recordarnos que "todo sistema económico exige una conducta ética y el capitalismo no es una excepción” 4 .

Bajo este escenario, lo ético corresponderá a la determinación, delimitación y análisis particular de cada una de las cargas axiológicas a las cuales el derecho termina haciendo referencia, a través de la denominada ética aplicada. Como nos enseña Cortina: "Lo específico de cada ética aplicada, lo que le presta su peculiar idiosincrasia, son los bienes internos que persigue la actividad correspondiente, los principios de nivel medio que orientan moralmente la acción, los valores que es necesario alcanzar y las virtudes que importa cultivar para alcanzar los bienes internos" ${ }^{35} \mathrm{~A}$ través de este modo, o como señalan Salazar y Rodríguez: "si se logra superar el mito según el cual ética, economía y finanzas son incompatibles, es posible romper paradigmas y buscar, desde una integración de las tres, su contribución a un desarrollo humano sostenible y equitativo"46.

Y así es que la noción de valor, en el contexto de una ética aplicada, es el elemento que termina por entregarnos un criterio objetivo para nuestra postura. Por ello los principios de ética comercial terminan haciendo referencia a valores tan importantes para el desarrollo de la actividad comercial como la confianza, la responsabilidad, la justicia, la honestidad, el respeto, la integridad, la lealtad, la tolerancia, la solidaridad, etcétera ${ }^{47}$.

\section{Lo jurídico: reglas limitativas con sentido y valor social}

$\mathrm{Y}$ frente a este escenario, ¿qué función o rol le corresponde cumplir al derecho? Nuestra opinión es que el derecho, en tanto ciencia de naturaleza social, será el encargado de conferir las reglas de conducta cuyo cumplimiento se espera poder alcanzar en aras de obtener el grado de

dividual que sea posible, sin medir satisfactoriamente las consecuencias o los efectos negativos de su actuar frente a terceros.

${ }^{44}$ GuZMán, Joaquín, cit. (n. 31), p. 18. En la misma línea de ideas, para GonZÁLEZ, María, cit. (n. 1), p. 247, sostiene que: "No es el modelo o las políticas económicas las que esencialmente generan pobreza, desempleo y mayor marginación sino que son las "imperfecciones normales" del mercado".

${ }^{45}$ Cortina, Adela, La dimensión pública de las éticas aplicadas, en Revista Iberoamericana de Educación 29 (2002), p. 55.

${ }^{46}$ Salazar, Gloria - Rodríguez, María, cit. (n. 22), p. 122.

${ }^{47}$ Cabe señalar que esta posición resulta muy semejante a lo que Cortina, Adela, Ética de la empresa. Claves para una nueva cultura empresarial (Madrid, Trotta, 2003), por su parte, entiende como ética de la empresa, desde el momento que la define como: "El descubrimiento y la aplicación de los valores y normas compartidos por una sociedad pluralista al ámbito peculiar de la empresa, lo cual requiere entenderla según un modelo comunitario”. 
cumplimiento de las reglas del mercado que resulten tolerables en un momento determinado ${ }^{48}$.

Lo anterior resulta paradójico para nuestra posición, ya que, al establecer reglas, el derecho termina generando limitaciones a partir de las cuales genera su actuar. De ahí que, para poder armonizar ambas posiciones, se requiere agregar otro elemento, el cual termina dando sentido y validez a nuestra posición, al considerar que las limitaciones que efectúa el derecho deben ser realizadas bajo un sentido y valoración social ${ }^{49}$.

Respecto al sentido social de la norma jurídica, esta no sería más que una consecuencia directa de la naturaleza social de la propia ciencia jurídica y de su aplicación en el ámbito de otras ciencias sociales - tal como lo es la economía- o de lo que algunos autores han denominado bienestar social o bien común ${ }^{50}$.

Así las cosas, la cultura mercantil de inicios del siglo XXI debiese tender al logro de verdaderos procesos de construcción asociativa que permitan mostrar el conjunto de valores compartidos por los miembros de una determinada actividad comercial, facilitando la asunción y los

${ }^{48}$ En una línea de argumentación parecida, pero restringida solamente al mercado de valores, García explicita que: "Se consideran prácticas abusivas del mercado aquellas que dañan la integridad de los mercados y la confianza de los inversores. La regulación define dos tipos de estas prácticas: el uso de información privilegiada y la manipulación de cotizaciones. A pesar de esta diferenciación, ambos tipos de prácticas pueden englobarse en el término de manipulación del mercado, ya que suponen una distorsión de la información disponible en el mercado y, por tanto, pueden provocar respuestas diferentes en los agentes participantes en la negociación" (GARCíA, María Nieves, cit (n. 7), p. 163).

${ }^{49}$ De ahí que López de Goicoechea -influenciado por la visión de A. Sen en "OnEthics and Economics" (Oxford, 1987) - nos ilumina al sostener que la salud del mercado radica en la correcta asimilación de la justicia distributiva: "Es decir, lo que se juegue en los mercados es lo que la política, a través del derecho, debe limitar en aras del interés común y, de forma especial, en interés de los más desfavorecidos in radice. De ahí que podamos aceptar que el mercado, cuando respeta las exigencias de la justicia distributiva, es la vía más adecuada para la realización de las preferencias individuales, pues de lo contrario no sería si no lo que Garzón Valdés llama tendencia suicida de toda sociedad democrática" (López DE GoicoecheA, Francisco, cit. (n. 9), p. 276).

${ }^{50}$ Según Guzmán: "La economía es el estudio de la humanidad en los asuntos ordinarios de la vida; y analiza la parte de la acción individual y social que está más conectada con el logro y el uso de los requisitos materiales del bienestar. Esta concepción de Marshall viene a coincidir en gran medida con la que mucho más tarde ofrecieron los notables economistas norteamericanos R. Heilbroner y W. Milberg: 'La Economía es el estudio del proceso de proporcionar el bienestar material de la sociedad' (Heilbroner, R. y Milberg,W., 1998)”. GuZmán, Joaquín, cit. (n. 31), p. 16. 
compromisos éticos que se adquieren en torno a ellos $^{51}$. Construcción colectiva que, en nuestro parecer, comparte la segunda característica del constructivismo ético propuesto por Rawls ${ }^{52}$, esto es, como nos recuerda Benfeld, ${ }^{53}$ la construcción de principios y normas morales que siguen un procedimiento que busca la construcción de una objetividad normativa a través de la interacción lingüística y social de un grupo de discusión que discute y delibera cooperativamente, siguiendo pautas de competencia e imparcialidad por parte de quienes intervienen. De este modo, se consigue una armonización de intereses particulares que contribuye al interés social.

\section{La autorregulación y los instrumentos jurídicos}

A partir de este punto, y al reconocer que el derecho debe ir por detrás de la axiología, le corresponderá hacerse cargo del análisis de los distintos instrumentos bajo los cuales cumple su aporte, y que en nuestra postura, coincide con el estudio de la naturaleza jurídica y efectos de la denominada autorregulación, y más particularmente, de su aplicación a través de sus diversas posibilidades, esto es: códigos de conducta, códigos de ética y/o códigos de buen gobierno corporativo ${ }^{54}$.

Ahora bien, cabe señalar que si bien es cierto que todos estos códigos tienen una diversa naturaleza ${ }^{55}$, gozan, por otro lado, de la misma fuente. En otras palabras, esta serie de instrumentos jurídicos a través de los cuales se manifiesta la autorregulación, cuenta con una raíz normativa común referida al denominado soft law de origen anglosajón, y en cuya virtud se advierte una mayor flexibilidad para poder incluir, modificar, o, en su caso,

${ }^{51}$ EINAR, Aadland, Values in professional practice: Towards a critical reflective methodology, en Journal of Business Ethics 97 (2010), 3, pp. 461-472.

${ }^{52}$ Rawls, John, Political Liberalism (Expanded Edition) (Columbia University Press, New York, 2005), pp. 448-449.

${ }^{53}$ Benfeld, Johann, El constructivismo ético en Justice as Fairness, en RDUCN. 2 (2012), pp. 83-117.

${ }^{54}$ En torno a la función que les corresponde cumplirá los denominados códigos de conducta en los mercados, GarCía, María Nieves, cit. (n. 7), p.177, entiende que: "La regulación de valores clasifica las infracciones en dos tipologías, el uso de información privilegiada y la manipulación de precios, que en terminología actual se engloban en el concepto de "abuso de mercado». Los códigos de los mercados pueden poner el énfasis en la perturbación que este tipo de prácticas provoca en su funcionamiento o pueden, también, resaltar la merma que suponen para la transparencia”.

${ }^{55}$ Efectivamente, en todos estos códigos es posible reconocer una diferencia género-especie, en virtud de la cual se distingue una relación que va desde lo general (conducta humana) a lo particular (correcta administración de una sociedad anónima). 
actualizar con una mayor rapidez todas aquellas conductas que puedan ser consideradas como valiosas para los diferentes grupos de interés en base a los cuales se estructuran tanto la actividad comercial, de manera general, como las diversas empresas, de manera particular ${ }^{56}$. Dichas conductas -desde nuestra posición- debieran contar con el sentido y el valor social al que hemos hecho referencia, si esperan gozar de un efectivo grado de cumplimiento por parte de sus destinatarios. En palabras sencillas, un código de este tipo adquiere validez no por su naturaleza normativa, sino porque contiene y es el fiel reflejo del sentir colectivo de los diversos grupos de interés, quienes, al participar en su elaboración e implementación, sienten como suyo tanto el contenido literal como el sentido axiológico de la norma. Como nos recuerda Bosi: "Es necesario adoptar una aproximación diferente a la cuestión de la ética de la empresa, que adopte una visión de carácter estructural, de forma tal que pueda verificarse en qué medida el derecho societario sirve para la introducción de componentes éticos en la empresa, aunque sea de forma indirecta, esto es, sin entrar en conflicto directo con los parámetros positivizados legalmente" 57 . A lo que agrega el mismo autor: "Se ha adquirido la conciencia de la utilidad de incentivar a las empresas por dotarse de modelos de autorregulación (no sólo de carácter estatutario, que también). Modelos que no tienen por qué ser uniformes, ni estar homologadas a ciertas prácticas societarias preconstituidas. Por el contrario, se ve la oportunidad de que los modelos de autorregulación den lugar a la máxima diferenciación posible entre las empresas, favoreciendo así el desarrollo de dinámicas concurrenciales entre los posibles y futuros inversores en el capital de aquellas sociedades que cuenten con modelos de autorregulación de carácter ético" 58 .

De esta forma, la autorregulación surge como alternativa eficaz y con auspicioso futuro para precisar cuáles serían las conductas que, en un momento, y dada la cultura organizacional idónea, puedan ser consideradas como contrarias a los principios de ética comercial, ya sea porque se adopte la fórmula genérica de los denominados códigos de conducta o códigos de buenas prácticas, o bien porque se opte derechamente por una vía más específica, como pueden ser los códigos de ética y/o de gobierno corporativo.

${ }^{56}$ Acerca de las raíces y función prelegislativa del denominado softlaw, recomendamos al lector ver: Kun, Attila, Innovadores métodos de regulación en la periferia del Derecho del trabajo: propuestas desde la responsabilidad social empresarial, softlaw, Derecho de la empresa, entre otros, en Revista Ius et Praxis 21(2015), 1, pp. 577-598.

${ }^{57}$ Bosi, Giacomo, El derecho mercantil entre la ética de los negocios y la responsabilidad social, en Revista de Fomento Social (2012), pp. 79-86.

${ }^{58}$ Bosi, Giacomo, cit. (n. 57), pp. 79-86. 


\section{PRINCIPIOS DE ÉTICA COMERCIAL EN LA LMV}

\section{Abusos de mercado, confianza y protección del inversionista}

Una vez establecido qué debe entenderse bajo la denominación principios de ética comercial para el derecho del mercado en general, todavía nos queda por resolver ¿cuál es la función que al respecto debe cumplir el denominado derecho del mercado de valores?

Para responder a esta interrogante, recordemos a Vásquez, quien a propósito del uso de información con carácter privilegiado en el mercado de valores, acertadamente nos recuerda que la sanción de este tipo de actuaciones se inserta dentro de un tema más amplio que se conoce como 'abusos de mercado', y que, en esencia, se trata de una conducta que, desde un punto de vista económico hace peligrar o lesiona la función pública de la información en cuanto criterio de justa distribución del riesgo negocial en el mercado de valores. Lo que se pretende por medio de su regulación, entonces, es preservar la confianza de los inversores y la integridad de los mercados, protegiendo al inversor frente a los riesgos que se derivan de la asimetría de la información, es decir, frente al peligro de que algunos inversores se vean perjudicados al no tener acceso a la información financiera o no ser capaces de utilizarla correctamente. Desde esta óptica, el bien jurídico protegido es el mecanismo de la libre formación de precios con el fin de garantizar la transparencia e igualdad de oportunidades entre los inversores" $"$.

Y bajo la mirada de los principios de la ética comercial, ¿qué debe entenderse cuando hablamos de confianza de los inversores, libre formación de precios, transparencia e igualdad de oportunidades? Respecto a este punto, nuestra postura es que nos debemos referir a los mismos "valoreséticos" de nivel moral de la actividad mercantil a los cuales hemos hecho mención a lo largo del presente trabajo, es decir, a todos aquellos que resultan capaces de superar el nivel meramente utilitario y técnico de los denominados "valores-precio". En términos prácticos, acciones u omisiones que, entre otros, resulten contrarios a los valores de confianza, justicia, responsabilidad, honestidad, respeto, integridad y lealtad.

\section{Otro ejemplo concreto: las actividades prohibidas bajo la LMV}

Junto a la serie de conductas sancionadas en relación al uso de información privilegiada, de conformidad a lo dispuesto en el título XXI

${ }^{59}$ VÁSQUEZ, María, Revisión del ámbito de aplicación subjetivo y objetivo de la noción de uso de información privilegiada en Chile: un examen de la normativa a la luz de las tendencias doctrinales y jurisprudenciales", en RDUCN. 17 (2010), 2, pp. 242-243. 
-artículos 164 y siguientes de la $\mathrm{LMV}^{60}$ - es posible visualizar un segundo caso concreto que refuerza normativamente la aplicación de nuestra postura, bajo lo que el título VIII de la LMV denomina en su epígrafe como: "De las actividades prohibidas"61. Para ello, la LMV se encarga de precisar una serie de conductas que se consideran prohibidas, todas las cuales perfectamente podrían ser consideradas como atentatorias de los ya latamente referidos principios de ética comercial, en tanto fiel reflejo de acciones $\mathrm{u}$ omisiones contrarias a valores de nivel moral como la justicia, la honestidad, y la lealtad ${ }^{62}$.

\section{CONCLUSIONES}

\section{Una sola mirada resulta insuficiente}

A lo largo de la presente investigación hemos podido vislumbrar que tanto el derecho como la economía son incapaces para poder desentrañar por sí solos qué debe entenderse bajo los denominados principios de ética comercial.

De la misma forma, esperamos haber podido demostrar que junto al

${ }^{60}$ Cabe recordar que de conformidad al artículo 164 de la LMV: "Para los efectos de esta ley, se entiende por información privilegiada cualquier información referida a uno o varios emisores de valores, a sus negocios o a uno o varios valores por ellos emitidos, no divulgada al mercado y cuyo conocimiento, por su naturaleza, sea capaz de influir en la cotización de los valores emitidos, como asimismo, la información reservada a que se refiere el artículo 10 de esta Ley. También se entenderá por información privilegiada, la que se posee sobre decisiones de adquisición, enajenación y aceptación o rechazo de ofertas especificas de un inversionista institucional en el mercado de valores".

${ }^{61}$ Comentando estas prohibiciones, Aimone, Enrique, cit. (n. 25), pp. 92-93, entiende que: "Por estas razones, la Ley de Mercado de Valores dispone la obligatoriedad o prohibición de ciertas conductas, por su efecto en este mercado tan especial. Estas normas pueden constituir -no obstante su carácter jurídico- una especie de ética del agente. Los términos no son contradictorios, ya que gran parte del derecho es ética. El derecho es un mínimo ético, pero en este caso, este mínimo exige un estándar más alto. Un primer punto se refiere a la información. Ella debe ser transparente y completa. Esto no es una novedad. Una especie frecuente de fraude consiste en ocultar información o procurar alguna que no corresponda a la verdad".

${ }^{62}$ De esta manera: i) El art. 52 prescribe como contrario a la ley efectuar transacciones en valores con el objeto de estabilizar, fijar o hacer variar artificialmente los precios; ii) $\mathrm{El}$ art. 53 en su inciso primero consagra como contrario a la Ley No 18.045 el efectuar cotizaciones o transacciones ficticias respecto de cualquier valor, ya sea que las transacciones se lleven a cabo en el mercado de valores o a través de negociaciones privadas; iii) Finalmente, el inciso segundo del artículo referido en el literal anterior prohíbe a cualquier persona efectuar transacciones o inducir o intentar inducir a la compra o venta de valores por medio de cualquier acto, práctica, mecanismo o artificio engañoso o fraudulento. 
aporte de dichas ciencias sociales se requiere agregar una tercera mirada cuya base se encuentra en la denominada ética aplicada, y gracias a la cual surge una relación de necesaria interdependencia entre dichas esferas. Esta relación resulta de suyo importante para el correcto funcionamiento del mercado en general y, más particularmente, si nos enfrentamos al denominado mercado de valores, en donde el precio de los títulos que se transan en él, se encuentran en directa relación con la cantidad de información que se encuentre disponible. Lo anterior, significa reconocer que existe una serie de intereses públicos comprometidos de los que el derecho debe hacerse cargo, ayudando a establecer todas aquellas reglas que permitan obtener una mejor labor de intermediación al interior del mercado.

Lo expuesto resulta especialmente relevante al considerar que el modelo económico bajo el cual se desenvuelve el mercado de valores en Chile se estructura a partir del ejercicio y la protección acérrima de la libertad individual, la que, como entendía Friedman, requiere de un conjunto de valores e instituciones políticas que la desarrollen favorablemente.

\section{Se requiere de una mirada mixta con inclusión de lo social}

Ahí es donde nuestra posición se aleja del pensamiento neoliberal, en cuanto entendemos que la mirada limitativa de las reglas jurídicas requiere de un valor y sentido social con base antropológica, y que, en consecuencia, no se agote en la concepción meramente normativa de dichos valores, acercándose más a lo que Rawls denominó como la noción de pueblo democrático ${ }^{63}$. Dicha comprensión implica reconocer la existencia de un sentido y valor social que precisamente permite que la norma jurídica tenga, al final de cuentas, general aceptación y alto cumplimiento por sus destinatarios, tal como se espera que pueda ocurrir con los cada vez más recurrentes códigos de buenas prácticas, códigos de ética y/o códigos de buen gobierno corporativo.

De esta forma surge una íntima relación entre derecho y ética, en cuya virtud la norma jurídica se blinda de la eficacia del sistema sancionador, pero al mismo tiempo se alimenta de una serie de principios que estarían radicados en el sentir de la inmensa mayoría de los agentes económicos, en base a la idea de que el bien común o colectivo se encuentra por sobre el interés individual de los agentes del mercado.

De ahí que nuestra postura considere la existencia de una mirada inclusiva que desde las ciencias sociales permita integrar de manera armónica

${ }^{63}$ Ver Rawls, John, The Independence of Moral Theory (Collected Papers, Edited by S. Freeman, Harvard University Press, 1999); Rawls, John, The Law of People (Boston, Harvard University Press, 2002), pp. 138-149; Rawls, John, Political Liberalism (Columbia University Press, New York, 2005), pp. 448-449. 
elementos jurídicos, económicos y filosóficos, pero sin que se pierda la naturaleza jurídica de la aproximación al problema. Esta visión social y antropológico-ética es la que debiera influir debidamente, y es también la que, de una u otra forma, termina delimitando el sentido, alcance y eficacia normativa de las disposiciones jurídicas.

\section{Queda pendiente determinar qué debe entenderse por valor para cada cultura empresarial en particular}

Con todo, todavía queda pendiente la realización de un estudio y análisis más detallado de un método que axiológica y jurídicamente pueda ser considerado como portador de valor para cada empresa en particular. Lo anterior, en tanto consideramos que los más altos principios de ética comercial no pueden quedar reducidos a una repetición de aspectos normativos que resultan claramente insuficientes para dar fondo al accionar ético que se espera suscitar. Especialmente, cuando esto se realiza sin mencionar qué cualidades objetivas son las que se consideran valores éticos y cómo ellas generan de manera efectiva ciertas obligaciones de actuación al interior de la respectiva organización.En dicha tarea, necesariamente, habrá de tenerse presente que todo este actuar se sostiene en consideraciones de raíz ética, por lo que su aplicación en cada empresa en particular debe incluir la debida y necesaria consecuencia que se desprende de la aplicación que surge desde la filosofía moral. Esta última, entendida como la matriz reflexiva tanto del contenido como de la justificación que lleva a jerarquizar los distintos valores que estén en juego bajo una lógica de constructivismo ético para una cultura empresarial determinada.

\section{BiBLIOGRAFÍA}

Aimone, Enrique, Actividades económicas reguladas. Teoría y casos (Valparaíso, Thomson Reuters, 2014).

Aimone, Enrique - Silva, Adolfo, La noción de Derecho Económico, en Revista de Derecho de la Pontificia Universidad Católica de Valparaíso 44 (2015).

Benfeld, Johann, El constructivismo ético en Justice as Fairness, en Revista de Derecho Universidad Católica del Norte 2 (2012).

Bosi, Giacomo, El derecho mercantil entre la ética de los negocios y la responsabilidad social, en Revista de Fomento Social (2012).

CACHÓn, José, Derecho del mercado de valores (Madrid, Dykinso, 1992), I.

Cortina, Adela, La dimensión pública de las éticas aplicadas, en Revista Iberoamericana de Educación 29 (2002).

Cortina, Adela, Ética de la empresa. Claves para una nueva cultura empresarial (Madrid, Trotta, 2003).

EINAR, Aadland, Values in professional practice:Towards a critical reflective methodology, en Journal of Business Ethics 97 (2010), 3.

Faúndez Allier, Juan-Pablo, La bioética de Diego Gracia (Madrid, Triacastela, 2014). 
FERnÁndez, Luis, Derecho, ética y negocios. Discurso de apertura del año académico 1993-1994. Disponible [en línea]: http://www.cervantesvirtual.com/obra-visor/ derecho-etica-y-negocios--0/html/ff26d288-82b1-11df-acc7-002185ce6064_1. html.

FERnÁNDEZ, Javier, La ética en los negocios (Barcelona, Ariel, 2001).

Friedman, Milton, Capitalismo y Libertad (Madrid, Ediciones Rialp, 1996).

García, María Nieves, Ética, equidad y normas de conducta en los mercados de valores: la regulación del abuso del mercado, en Ética y Economía 823 (2005).

García-Marzá, Domingo, Ética empresarial. Del diálogo a la confianza (Madrid, Trotta, 2004).

Gaspar, José Antonio - Araya, Fernando, Derecho corporativo y de libre competencia, en Revista Chilena de Derecho Privado 17 (2011).

GonZÁlez, María, Ética de la economía, sujeto y derechos humanos, en Polis, Revista de la Universidad Bolivariana 11 (2012), 33.

GuZMÁn, Joaquín, El Rol de la Ética en la ciencia económica en Información Comercial Española, en Revista de economía 823 (2005).

GuZMÁn, Alejandro - Guerrero, José Luis, La sustitución de la noción de "título-valor" por "valores negociables" en la ley de mercado de valores de España, como base para la delimitación de un derecho del mercado de valores, en RDUCN. 24 (2017), pp. 211-237.

GuZmán, Alejandro - Guerrero, José Luis, La noción de "valor" como objeto de transacción en el mercado de valores según el derecho chileno, en RDPUCV. 47 (2016).

Kun, Attila, Innovadores métodos de regulación en la periferia del Derecho del trabajo: propuestas desde la responsabilidad social empresarial, softlaw, Derecho de la empresa, entre otros, en Revista Ius et Praxis 21 (2015), 1.

Lidón, Jesús:, Conceptos básicos de Economía, Valencia (Valencia, Universidad Politécnica de Valencia, 1998).

LocKe, John, Segundo tratado sobre el gobierno civil (Madrid, Alianza Editorial, 1990).

López de GoicoecheA, Francisco, Ética y mercado de valores, en Revista de Ciencias Sociales y Humanidades 92 (2003).

Menchaca, Tomás, La Ética Económica: sus aspectos fundamentales, en Revista de Derecho, Facultad de Ciencia Jurídicas y Sociales Universidad Austral de Chile 3 (1992), 1-2.

Mill, John Stuart, El utilitarismo (Madrid, Alianza Editorial, 1984).

Morrós, Jordi, Responsabilidad Social Corporativa (Madrid, FC Editorial, 2005).

OlCESE, Aldo, Manual de la empresa responsable y sostenible (Madrid, McGraw Hill, 2008).

RaWls, John, The Independence of Moral Theory (Collected Papers, Edited by S.

Freeman, Harvard University Press, 1999).

Rawls, John, The Law of People (Boston, Harvard University Press, 2002).

RAwls, John, Political Liberalism (Expanded Edition) (Columbia University Press,

New York, 2005).

Rousseau, Jean-Jacques, El contrato social (Barcelona, Orbis, 1984).

SALAzAr, Gloria - Rodríguez, María, La ética y los profesionales del mercado de valores. Investigación en cuatro ciudades de Colombia, en Cuadernos de administración 25 (2012), 44. 
SARABiA, Silvana, La enseñanza de la ética y la conducta humana, en Revista Médica Herediana (2001).

Scheler, Max, Ética (Madrid, Caparrós, 2001).

Sen, Amartya, On Ethics and Economics (Oxford, Basil Blackwell, 1987).

Sen, Amartya, Desarrollo y libertad (Barcelona, Planeta, 2000).

Sierra, Ángela, Mercado y valores éticos, en Jornadas de formación de la comisión general de justicia y paz. (2011). Disponible [en línea]: http://justiciaypaz.dominicos.org/ kit_upload/PDF/jyp/Realidades\%20Sociales/MercadosEtica.pdf.

SILVA, Berta, Metodología de la OCDE para la evaluación de principios de Gobiernos Corporativos (Santiago, Thomson Reuters, 2011).

Sмiтh, Adam, Teoría de los sentimientos morales (Madrid, Alianza, 2004).

SMITH, Adam, Investigación sobre la naturaleza y causas de la riqueza de las naciones (Madrid, Tecnos, 2009).

TRUCCO, Eduardo, Las bolsas de valores y su reglamentación: inversionistas, corredores de bolsa, emisores de valores (Santiago, Editorial Jurídica, 1989).

VÁsQUEZ, María, Revisión del ámbito de aplicación subjetivo y objetivo de la noción de uso de información privilegiada en Chile: un examen de la normativa a la luz de las tendencias doctrinales y jurisprudenciales, en Revista de Derecho Universidad Católica del Norte 17 (2010), 2. 